\title{
Pathological correlation between needle biopsy and radical prostatectomy specimen in patients with localized prostate cancer
}

\author{
Muhammad A. Bulbul, MD, FRCSC; ${ }^{*}$ Yaser El-Hout, MD; ${ }^{*}$ Maurice Haddad, MD; ${ }^{+}$Ayman Tawil, MD; ${ }^{+}$ \\ Ali Houjaij, MD; ${ }^{*}$ Nizar Bou Diab, MD; ${ }^{*}$ Oussama Darwish, MD*
}

\section{ABSTRACT}

Objective: This study aims to evaluate the accuracy of transrectal ultrasound (TRUS) guided prostate biopsies in predicting pathological grading and tumour distribution in the final pathological specimen of patients who underwent radical prostatectomy for clinically localized prostate cancer. The study ultimately aims to gain more understanding of the pathological behaviour of prostate cancer and the limitations of the currently available diagnostic and prognostic tools.

Material and Methods: We reviewed the records of 100 patients with localized carcinoma of the prostate diagnosed by TRUS-guided prostate biopsy and treated with radical retropubic prostatectomy, comparing tumour laterality and Gleason score in core biopsies with tumour distribution and Gleason score of the surgical specimen. We then correlated both results to diagnostic and prognostic variables such as prostate specific antigen (PSA) values and surgical margins.

Results: All 44 patients with bilateral disease on needle biopsy had bilateral disease on final pathology, with 15 of these patients (34\%) having positive margins. Of the 56 patients with unilateral disease on biopsy, 37 (66\%) had bilateral disease on final pathology; however, only 4 of them ( $7 \%$ ) had positive margins $(p<0.001)$. Median Gleason score on final pathology was upgraded to 7, compared with a median score of 6 on biopsies. Stratifying patients to 2 groups based on their PSA level (group 1: PSA $<10 \mathrm{ng} / \mathrm{mL}, 72$ patients; group 2: PSA $>10 \mathrm{ng} / \mathrm{mL}, 28$ patients), revealed that 57 patients $(79 \%)$ in group 1 and 24 patients (85\%) in group 2 had bilateral disease. In addition, 13 patients $(18 \%)$ in group 1 and 6 patients $(21 \%)$ in group 2 had positive margins.

Conclusions: Sixty-six percent of patients with unilateral disease on needle biopsy had bilateral disease on final pathology, but this does not increase their rate of having positive margins. Gleason score is upgraded from 6 to 7. PSA did not seem to affect laterality of disease in patients selected for radical prostatectomy.

CUAJ 2007;1(3):264-6

\section{Introduction}

Prostate cancer is often a bilobar disease that might not be initially captured on the diagnostic transrectal ultrasound (TRUS) guided needle biopsy. ${ }^{1-3}$ Pathological staging is one of the critical predictors of outcome in patients with prostate cancer. ${ }^{4-7}$ The Gleason score of the final surgical specimen has been proven a reliable predictor of survival; however, the Gleason grading of the biopsy cores and tumour laterality often differ from the grading and tumour site in the prostatectomy specimen. ${ }^{8-11}$ Within the context of the currently available radical therapies for prostate cancer and the boom in clinical screening using prostate specific antigen (PSA) as well as the concomitant increase in patients undergoing TRUS-guided prostate biopsies, ${ }^{12-15}$ it was crucial to evaluate the accuracy of biopsy in predicting pathological grading and extent of disease in the final surgical pathological specimen. We elected to study the biopsy specimen compared with the surgical pathological specimen correlation and its implications in patients with clinically localized prostate cancer who were treated with radical prostatectomy.

\section{Material and Methods}

This is a single centre retrospective study in which the medical records, including the pathology reports, of 100 consecutive patients who underwent radical retropubic prostatectomy following diagnosis of prostate cancer by TRUS-guided prostate biopsy were reviewed. Patients ranged in age from 46 to 71 years (median $62.5 \mathrm{yr}$ ) and in PSA from $2 \mathrm{ng} / \mathrm{mL}$ to $56 \mathrm{ng} / \mathrm{mL}$ (median $6.85 \mathrm{ng} / \mathrm{mL}$ ). All patients had clinically organ confined disease on the preoperative evaluation. All patients had at least 12 cores in 4 zone biopsies; 3 cores (apex, middle and base) from each of the 4 zones (right peripheral, right transitional, left peripheral and left transitional) were taken. All biopsies were performed using the 18-gauge, 2-cm long, Trucut core needle biopsy under ultrasound guidance, with a Phillips ATL HDI 3500 ultrasound machine (Phillips, US, 1986) and a C-9-5 MHz endorectal probe. Prior to biopsy, all patients 
received appropriate antibiotic coverage and selected patients had bowel preparation. Biopsy evaluation included Gleason score, lateral location, number of positive cores and the amount of cancer within each positive core in $10 \%$ increments. All patients had retropubic, nerve sparing (when appropriate) radical prostatectomy. No patient had hormone deprivation therapy. Pathological examination was performed by experienced pathologists without consensus interpretations and without revision of the Gleason score based on surgical findings. The surgical specimens were processed in a standard manner, including serial sectioning of the gland and sampling of each representative portion. Pathological evaluation focused on Gleason score, laterality, percentage of tumour and positive margins.

\section{Results}

None of the patients experienced significant biopsyrelated morbidity; specifically, no cases of urinary retention or urinary tract infection occurred. Of the 100 patients, 56 had unilateral disease and 44 had bilateral disease on biopsy. All 44 patients with bilateral disease on biopsy had bilateral disease on final pathology, with 15 of them (34\%) having positive margins. Of the 56 patients with unilateral disease on biopsy, 37 (66\%) had bilateral disease on final pathology, yet only 4 of them $(7 \%)$ had positive margins $(p<0.001)$ (Table 1$)$. Median Gleason score on final pathology was upgraded to 7 , compared with a median score of 6 on biopsies. Stratifying patients to 2 groups based on their PSA level (group 1: PSA $<10 \mathrm{ng} / \mathrm{mL}, 72$ patients; group 2: PSA $>10 \mathrm{ng} / \mathrm{mL}, 28$ patients), revealed that 57 patients (79\%) in group 1 and 24 patients (85\%) in group 2 had bilateral disease. In addition, 13 patients $(18 \%)$ in group 1 and 6 patients $(21 \%)$ in group 2 had positive margins (Table 2 ).

\section{Discussion}

Prostate cancer is the most common malignant tumour in men and the second most common cause of cancer death. ${ }^{16-18}$ There is extensive literature on many aspects of this disease, but relatively little has been written on the diagnosis, grading and prognostic value of prostate cancer diagnosed in core needle biopsies. Ongoing evaluation of the currently available diagnostic and prognostic tools is crucial. Studies have shown that biopsy grading, when compared with matched surgical grades, suffers from significant rate of undergrading, ranging from $27 \%$ to $57 \% .{ }^{19-22}$ In line with this, our study shows an upgrading in median Gleason score from 6 to 7 . This discordance is related to the fact that prostate cancer is multifocal, with a heterogeneous population of tumour cells. This may result in sampling an area that is overrepresented with high-grade disease or, conversely, overrepresented with low-grade disease, compared with the histological grade of the resected prostate. ${ }^{23-25}$ Similarly, because prostate cancer is multifocal, the surgical specimen often shows bilateral disease. Whenever it is misinterpreted as unilateral on the biopsy specimen, it would be secondary to a lateral small volume of cancer that was not adequately sampled and missed by the needle..26,27 Hence, reasons for grade discrepancies between biopsies and surgical specimens include biases in pathological interpretation and sampling effects. The quantity of cancer within biopsy cores and the needle gauge used were not shown to affect grading accuracy in several large series. ${ }^{28-30}$ Studies have shown that employing more biopsy cores may minimize discrepancy owing to sampling effects. This can be demonstrated by applying Bayes' conditional probability theorem with the equation $p=1-(1-v)^{n}$, where $p$ represents the probability of a positive core in a patient with cancer, $v$ the volume of cancer as a percent-

\begin{tabular}{|c|c|c|}
\hline \multirow[b]{2}{*}{$\begin{array}{l}\text { Pathology } \\
\text { specimen }\end{array}$} & \multicolumn{2}{|c|}{ Needle biopsy } \\
\hline & $\begin{array}{l}\text { Unilateral disease } \\
\qquad(n=56) ; \\
\text { no. (and \%) }\end{array}$ & $\begin{array}{c}\text { Bilateral disease } \\
\qquad(n=44) ; \\
\text { no. (and \%) }\end{array}$ \\
\hline Bilateral disease* & $37(66)$ & $44(100)$ \\
\hline Positive margint & $4(7)$ & $14(34)$ \\
\hline
\end{tabular}

\begin{tabular}{|c|c|c|}
\hline \multirow[b]{2}{*}{ Pathology specimen } & \multicolumn{2}{|c|}{ Group, no. (and \%) } \\
\hline & $1(n=72)^{*}$ & $2(n=28) \dagger$ \\
\hline Bilateral diseaseł & $57(79)$ & $24(85)$ \\
\hline Positive margin§ & $13(18)$ & $6(21)$ \\
\hline \multicolumn{3}{|c|}{$\begin{array}{l}\text { PSA = prostate specific antigen. } \\
\text { *Group } 1 \text { included patients with a PSA level of }<10 \mathrm{ng} / \mathrm{mL} . \\
\text { tGroup } 2 \text { included patients with a PSA level of }>10 \mathrm{ng} / \mathrm{mL} \text {. } \\
\text { \#Bilateral disease detected in final pathology specimen. } \\
\S p \text { value not significant. }\end{array}$} \\
\hline
\end{tabular}


age of the gland and $n$ the number of biopsies. Mathematically, this shows that more biopsies will increase the yield of cancer detection and, for a given volume of cancer present, will sample a greater fraction of such cancer. ${ }^{31,32}$ Moreover, adopting a protocol based on consensus reporting by pathologists and using cytokeratin staining may minimize interpretation biases and observer variability. ${ }^{33}$

In conclusion, this study shows that in $66 \%$ of the cases, TRUS-guided biopsies predicted unilateral disease when bilateral disease existed. A unilateral positive biopsy does not predict unilateral disease. However, a unilateral positive biopsy correlates, with statistical significance, with a negative surgical margin, probably because a unilateral positivity reflects a small volume disease and organ confinement. PSA level did not seem to affect laterality of disease or surgical margin in patients undergoing radical prostatectomy. Finally, a well-differentiated tumour in the biopsy core is a poor predictor of a well-differentiated tumour or of organ confined disease in the surgical specimen. However, a high Gleason score on the biopsy is usually associated with disease outside the prostate and of a poorly differentiated tumour in the surgical specimen.

From the *Department of Surgery, Division of Urology, the †Department of Diagnostic Radiology and the ‡Department of Pathology and Laboratory Medicine, American University of Beirut-Medical Center, Beirut, Lebanon

This article has been peer reviewed.

Competing interests: None declared.

\section{References}

1. German R, Thompson T, Stewart S, et al. Distribution of male genital system cancers (MGSC), United States - 1999-2001. Ann Epidemiol 2005; 15:633-4.

2. Kronz JD, Milord R, Wilentz R, et al. Lesions missed on prostate biopsies in cases sent in for consultation. Prostate 2003;54:310-4.

3. Djavan B, Mazal P, Zlotta A, et al. Pathological features of prostate cancer detected on initial and repeat prostate biopsy: results of the prospective European Prostate Cancer Detection Study. Prostate 2001;47:111-7.

4. Montie JE. Current prognostic factors for prostate carcinoma. Cancer 1996;78:341-4.

5. Hutter RVP, Montie JE, Busch C, et al. Workgroup 3. Current prognostic factors and their relevance to staging. Cancer 1996;78:369-71.

6. Epstein JI. The diagnosis and reporting of adenocarcinoma of the prostate in core needle biopsy specimens. Cancer 1996;78:350-6.

7. Gonzalgo ML, Bastian P, Mangold L, et al. Relationship between primary Gleason pattern on needle biopsy and clinicopathologic outcomes among men with Gleason score 7 adenocarcinoma of the prostate. Urology 2006;67:115-9.

8. Catalona W, Stein A, Fair W. Grading errors in prostatic needle biopsies: relation to the accuracy of predicting lymph node metastasis. J Urol 1982;127:919-27.

9. Spires SE, Cibull ML, Wood DP, et al. Gleason histologic grading in prostatic carcinoma.
Correlation of 18-gauge core biopsy with prostatectomy. Arch Pathol Lab Med 1994; 118:705-8.

10. Narayan $P$, Gajendran $V$, Taylor $S$, et al. The role of transrectal ultrasound- guided biopsy-based staging, preoperative serum prostate-specific antigen, and biopsy Gleason score in prediction of final pathologic diagnosis in prostate cancer. Urology 1995;46:205-12.

11. Kojima M, Troncoso P, Babaian RJ. Use of prostate-specific antigen and tumor volume in predicting needle biopsy grading error. Urology 1995;45:807-12.

12. Littrup PJ, Bailey SE. Prostate cancer: the role of ultrasound and its impact on cancer detection and management. Radiol Clin North Am 2000;38:87-113.

13. Partin AW, Stutzman RE. Elevated prostate-specific antigen, abnormal prostate evaluation on digital rectal examination and transrectal ultrasound and prostate biopsy. Urol Clin North Am 1998;25:581-9.

14. Mian B, Lehr D, Moore C, et al. Role of prostate biopsy schemes in accurate prediction of Gleason scores. Urology 2006;67:379-83

15. Cooner WH. Prostate cancer detection in a clinical urologic practice by ultrasonography, digital rectal examination and prostate-specific antigen. J Urol 1990;143:1146-52.

16. Wingo PA, Tong T, Bolden S. Cancer statistics 1995. CA Cancer I Clin 1995;45:8-30.

17. Andrén 0 , Fall K, Franzén L, et al. How well does the Gleason score predict prostate cancer death? A 20-year follow-up of a population based cohort in Sweden. J Urol 2006; 175:1337-40.

18. Landis SH, Murray T, Bolden S, et al. Cancer statistics 1998. CA cancer J Clin 1998;48: 6-29.

19. Gleason DF. Undergrading of prostate cancer biopsies: a paradox inherent in all biologic bivariate distributions. Urology 1996;47:289-91.

20. Allsbrook W Jr, Mangold K, Johnson M, et al. Interobserver reproducibility of Gleason grading of prostatic carcinoma: general pathologist. Hum Pathol 2001;32:81-8.

21. Thickman D, Speers WC, Philpott PJ, et al. Effect of the number of core biopsies of the prostate on predicting Gleason score of prostate cancer. J Urol 1996;156:110-3.

22. Cookson MS, Fleshner NE, Soloway SM, et al. Correlation between Gleason score of needle biopsy and radical prostatectomy specimen: accuracy and clinical implications. J Urol 1997; 157:559-62.

23. King CR, Long JP. Prostate biopsy errors: a sampling problem? Int J Cancer 2000;90: 326-30.

24. Gleason DF. Histologic grading of prostate cancer: a perspective. Hum Pathol 1992;23:273-9.

25. Eichler $K$, Hempel S, Wilby J, et al. Diagnostic value of systematic biopsy methods in the investigation of prostate cancer: a systematic review. J Urol 2006;175:1605-12.

26. Buyyounouski M, Horwitz E, Hanlon A, et al. Positive prostate biopsy laterality and implications for staging. Urology 2003;62:298-303.

27. Gregori A, Vieweg J, Dahm P, et al. Comparison of ultrasound-guided biopsies and prostatectomy specimens: predictive accuracy of Gleason score and tumor site. Urol Int 2001; 66:66-71.

28. King CR. Patterns of prostate cancer biopsy grading: trends and clinical implications. Int $J$ Cancer 2000;90:305-11.

29. Bostwick DG. Gleason grading of prostate needle biopsies: correlation with grade in 316 matched prostatectomies. Am J Surg Pathol 1994;18:796-803.

30. Steinberg DM, Sauvegeot BS, Piantadosi S, et al. Correlation of prostate needle biopsy and radical prostatectomy Gleason grade in academic and community settings. Am J Surg Pathol 1997;21:566-76.

31. Stricker HJ, Ruddock $\mathrm{L}$, Wan J, et al. Detection of non-palpable prostate cancer: a mathematical and laboratory model. Br J Urol 1993;71:43-6.

32. Bostwick D, Meiers I. Prostate biopsy and optimization of cancer yield. Eur Urol 2006; $49: 415-7$.

33. Carlson GD, Calvanese CB, Kahane $H$, et al. Accuracy of biopsy Gleason scores from a large uropathology laboratory: use of a diagnostic protocol to minimize observer variability. Urology 1998:51:525-9.

Correspondence: Dr. Muhammad A. Bulbul, Clinical Professor, Department of Surgery, Division of Urology, American University of Beirut-Medical Center, PO Box 11-0236, Riad Solh 1107 2020, Beirut, Lebanon; mb30@aub.edu.lb 